\title{
NON-CHROMOSOMAL ENTITIES IN MITOSIS AND MEIOSIS OF BROMUS ARIZONICUS*
}

\author{
MARTA SHERMAN WALTERS \\ Santa Barbara Botanic Garden, Santa Barbara, Calif., U.S.A. and \\ Department of Biological Sciences, University of California, Santa Barbara
}

Received 15.i.66

\section{INTRODUCTION}

A number of inclusions are observed in the nuclei and cytoplasm of mitotic and meiotic cells of Bromus arizonicus. The most prominent of these is the structure called a " nuclear body", which is present in each microsporocyte (Walters, I963). The nuclear body is composed of RNA, proteins and phospholipids, and arises during the earliest stages of meiosis, possibly from materials released by the chromosomes (Walters, 1966). There are also numerous small entities which may be described as "globules" that appear and disappear during various stages of mitosis and meiosis. This study compares the globules in mitosis and meiosis, considers their possible relationship with known synthetic activities of cells in division, and compares the globules and nuclear body.

\section{MATERIALS AND METHODS}

The descriptions of globules are based on studies of three plants of Bromus arizonicus $(2 n=84), 62020,62022$, and 62027 . Following methods described by Rattenbury (1952), spikelets were fixed for about 24 hours in a mixture of 2 parts 95 per cent. ethyl alcohol : I part 40 per cent. formalin +5 per cent. glacial acetic acid, and stored in 70 per cent. alcohol under refrigeration. Anthers were hydrolysed for 2 hours in IN $\mathrm{HCl}$ at $60^{\circ} \mathrm{C}$. and then squashed in iron-acetocarmine.

Cytochemical tests for nucleic acids were made with material from several plants of $B$. arizonicus, including 62020 and 62027 . Spikelets were fixed in a mixture of 3 absolute ethyl alcohol : I glacial acetic acid and stored in 70 per cent. alcohol under refrigeration. In order to facilitate spreading and flattening the cells, anthers were macerated in stomach liquid of the snail Helix aspersa, then spread in a single layer of cells on the slide (Fabergé, r945; Walters, 1966). To test for RNA, p.m.c's were stained in a $0.25 \mathrm{mg} . / \mathrm{ml}$. solution of Azure B in $0.1 \mathrm{M}$ potassium citrate buffer at $p \mathrm{H} 4.0$ at $40^{\circ} \mathrm{C}$. (Flax and Himes, 1952). For the Feulgen test, p.m.c's were hydrolysed for to minutes in $1 \mathrm{~N} \mathrm{HCl} \mathrm{at} 60^{\circ} \mathrm{C}$., stained in leuco-basic fuchsin for 2 hours, washed in $\mathrm{SO}_{2}$ water and then in distilled water, transferred through an alcohol series and mounted in euparal.

\section{OBSERVATIONS}

The method developed by Rattenbury (1952) stains the globules without staining chromosomes. Although the chromosomes were not

* This investigation was supported in part by Public Health Service Research Grant No. $K_{3}-$ GM-729 from the National Institute of General Medical Sciences and in part by Research Grant GB-609 from the National Science Foundation. 
visible with either bright-field or phase-contrast microscopes, stages from prophase to telophase were recognised by the presence of nucleoli, spindle fibres or phragmoplasts. Pre-meiotic interphase and early prophase stages were identified by comparison with non-hydrolysed sister anthers or longitudinal halves of individual anthers or by position in the spikelet.

Pre-meiotic mitosis. In the interphase preceding the last pre-meitotic mitosis there were numerous tiny globules inside the nucleus (textfig. $I$, a) and none outside the nucleus. The globules became faintstaining and disappeared during the ensuing prophase. A few globules appeared in some cells at metaphase and early anaphase (text-fig. I, b) and more were present during anaphase and early telophase (textfig. I, c, d). At telophase the presence of globules at the poles was obscured by diffuse dark-st aining material-probably " prenucleolar" material (Lafontaine and Chouinard, 1963). After the nucleoli had formed and the prenucleolar material diminished, some tiny globules were observed in the nuclei, and some of those outside the nuclei appeared to have fused (text-fig. I, e).

Meiosis. In very early pre-meiotic interphase a number of tiny globules were scattered through the nucleus (text-fig. I, f); none were present in the cytoplasm. Globules were somewhat fewer and some were larger at late pre-meiotic interphase or early leptotene (text-fig. $I, g$ ). During late leptotene and early zygotene the structure called a "nuclear body " formed, apparently by aggregation of a number of globuleprimordia (text-fig. I, h, i) (Walters, I966). A single nuclear body was present at late zygotene and at subsequent stages through telophase-II.

Separate glcbules were not found in pachytene or diplotene. At diakinesis numerous tiny globules were scattered throughout the nucleus (plate $I$; text-fig. $I, j$ ). These varied somewhat in size, and were usually paired but occasionally single (or perhaps one lay directly above another). It could not be determined whether the location of globules and bivalents was the same, but in some instances there were clearly more pairs of globules than chromosomes. In anthers with diplotene and diakinesis stages, paired globules were absent in some microsporocytes or very few and faint-staining, or numerous and darkstaining in others. In anthers containing diakinesis and metaphase, numerous dark-staining paired globules were present in each microsporocyte in diakinesis. In very late diakinesis cells there were fewer globules and some were considerably larger than those in earlier diakinesis cells. From these observations it appeared that globules arose during diakinesis and some fused during late diakinesis. These globules were still present during that period of pro-metaphase after the nucleolus had disappeared and before the spindle had formed, but no globules were present after the spindle had formed at the beginning of metaphase or subsequently during metaphase.

At anaphase-I numerous single globules appeared that were somewhat variable in size (text-fig. I, $\mathrm{k}$ ); most were located near the poles. 


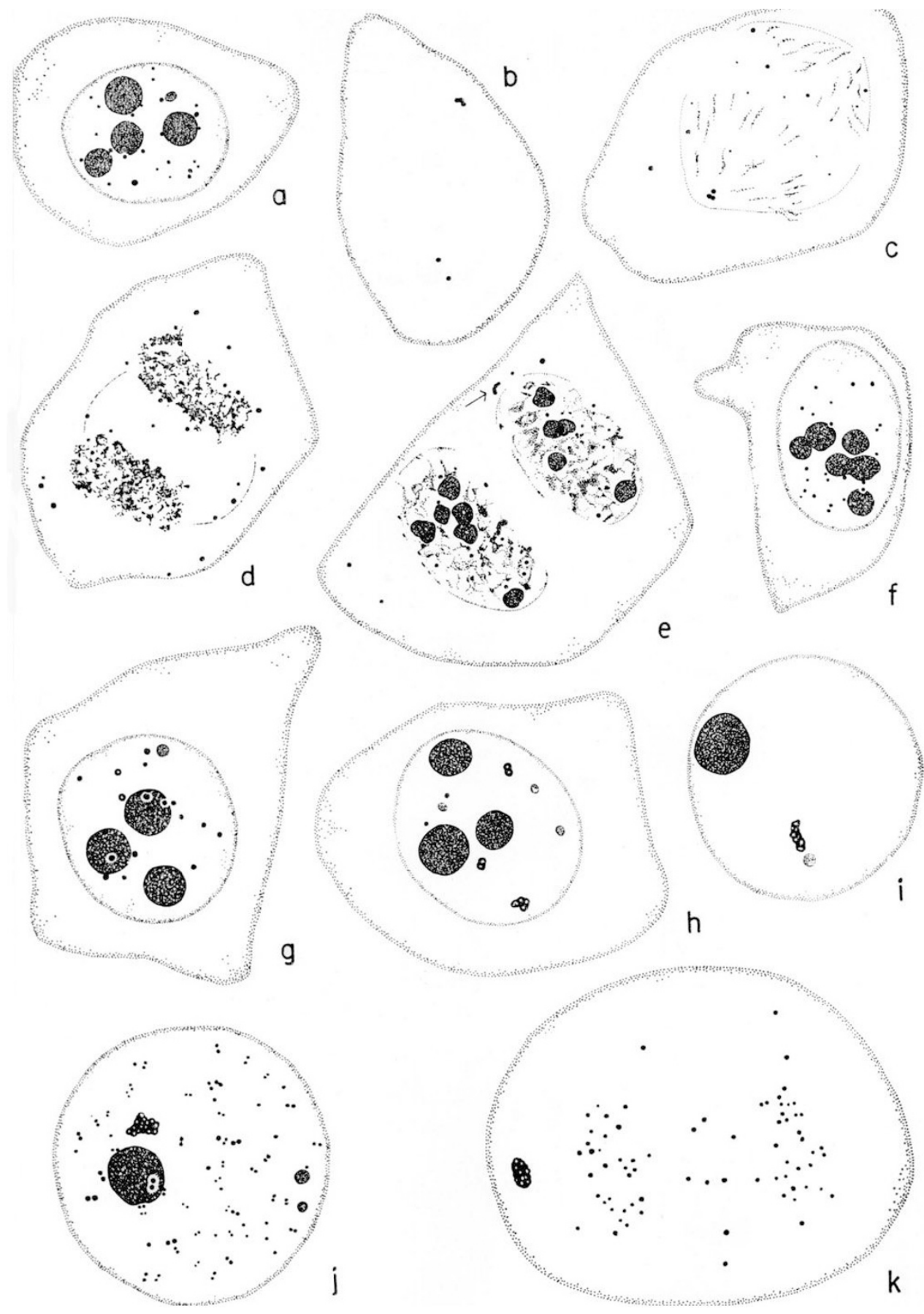

FIG. 1.-a-k, $\times 1000$.
a. Pre-meiotic mitosis, interphase.
b. Pre-meiotic mitosis, late metaphase or early anaphase.
c. Pre-meiotic mitosis, anaphase.
d. Pre-meiotic mitosis, late anaphase or early telophase.
e. Pre-meiotic mitosis, late telophase; arrow indicates fused globules.
f. Pre-meiotic interphase.
g. Late pre-meiotic interphase or early leptotene.
h. Late leptotene.
i. Nucleus in earıy zygotene.
j. Nucleus in diakinesis.
k. Anaphase-I. 


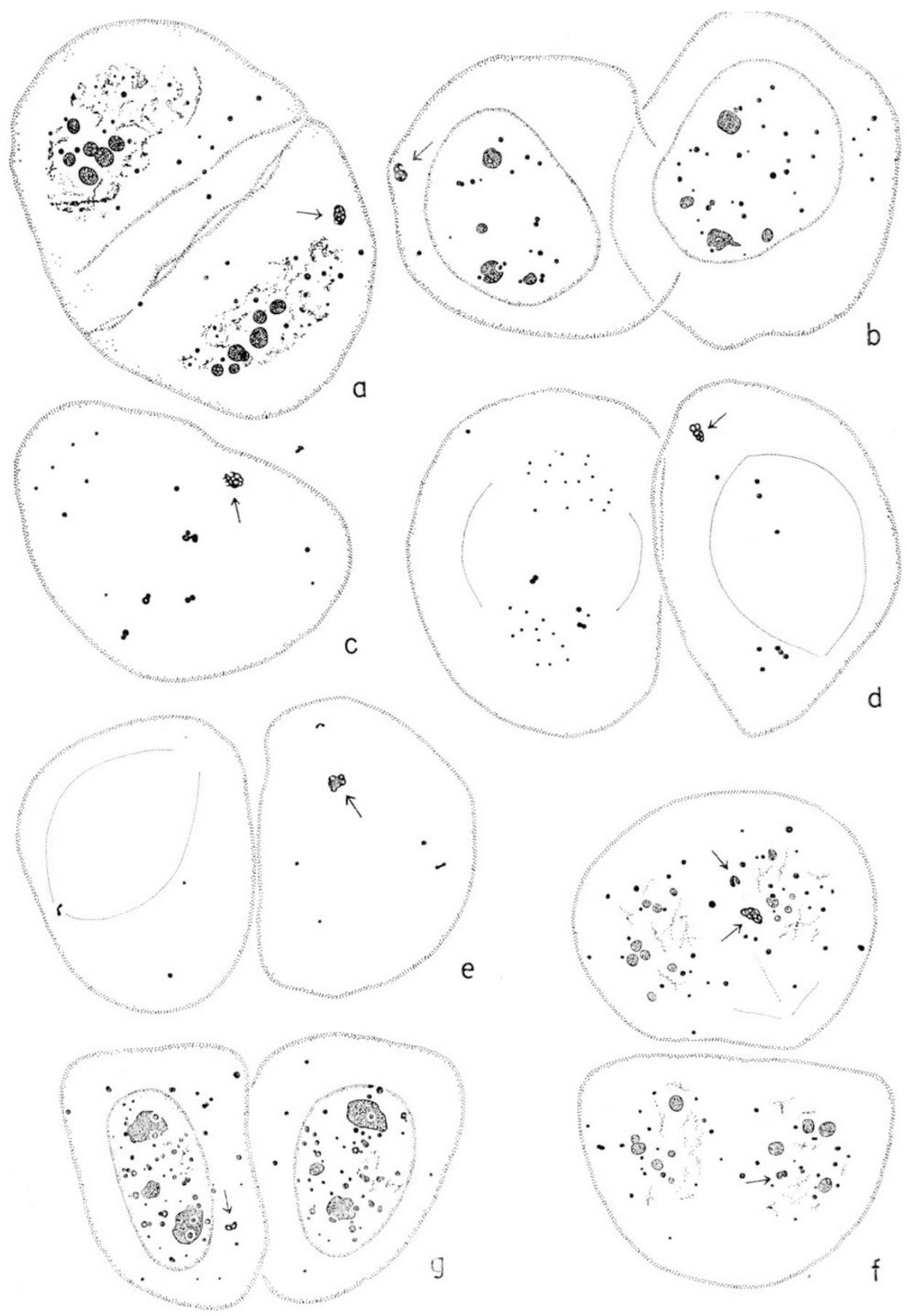

Fig. 2.-a-g, $\times 1000$.

a. Interphase-I; arrow indicates nuclear body.

b. Dyad at late prophase-II; arrow indicates nuclear body.

c. One cell of a dyad, probably in late anaphase-II; arrow indicates nuclear body; several compound bodies are at the equator and single globules are at the poles.

d. Left cell of dyad in late anaphase-II; right cell probably in late metaphase-II or early anaphase-II; arrow indicates nuclear body.

e. Dyad in metaphase-II; arrow indicates nuclear body.

f. Dyad in late telophase-II; center arrow indicates nuclear body; other arrows indicate small aggregate bodies.

g. Two cells of a quartet, probably in late interphase-II; arrow indicates remnant of nuclear body. 
At early telophase, when the phragmoplast was present but nucleoli had not yet begun to form, there were some globules inside and outside the nuclear areas; those inside were somewhat obscured by prenucleolar material. Globules were present in daughter nuclei at interphase-I and prophase-II and a few remained in the cytoplasm (text-fig. 2, a, b). Some globules at prophase-II appeared to be paired. Most of them had disappeared by the end of prophase, but a few were still present at metaphase-II (text-fig. 2e). At anaphase-II (text fig. 2d, right cell) there were some globules that generally appeared to lie outside the spindle. At late anaphase-II or early telophase-II (text fig. $2 \mathrm{~d}$, left cell) there were many tiny globules near the poles and some bodies in various regions of the cell appeared to be aggregates of larger globules (text-fig. 2, c). At a later stage of telophase-II, when nucleoli were forming, there were numerous globules of various sizes, some probably inside the nuclear area and some clearly outside, and sometimes one or more small aggregates (text-fig. 2, f). In interphase in the quartet there were numerous globules inside and outside the nuclei (text-fig. 2, g); no aggregate bodies remained.

The number of globules varied among microsporocytes of the same plant, to some extent in interphase and prophase, and to a greater extent in anaphase-II and telophase-II. The amount of variation within the species was not determined, but one of the plants studied had fewer globules and small aggregates in anaphase-II and telophaseII than the other two.

Rattenbury (1952) suggested that staining of nucleoli after his treatment might be due to the presence of lipoproteins. In this event the staining of globules may also be attributed to lipoprotein constituents. Tests for nucleic acids were not generally informative. Globules closely associated with chromosomes were hidden by the deeply-stained chromosomes. After the Feulgen treatment those globules or aggregates present in the cytoplasm of microsporocytes from metaphase-II to the quartet were not stained. There is thus no evidence that these globules contain DNA. After Azure B treatment they could not be distinguished among the numerous cytoplasmic granules of various sizes that stained metachromatically. Globules are present when active RNA synthesis occurs (see Discussion) and it is not improbable that they contain RNA as well as lipoprotein.

\section{DISCUSSION}

A comparison of globules in pre-meiotic mitosis, meiosis-I, and meiosis-II is shown in text-fig. 3. The situation in pre-meiotic mitosis appears basically the same as that in meiosis-II: globules are present in nuclei in interphase and prophase, they diminish or disappear during metaphase, and globules appear again during anaphase and telophase. The assumption is made that interphase-I and prophase-II are relatively short stages, and there are some globules in the cytoplasm at prophaseII and early metaphase-II because there has not been sufficient time 
for their dissolution. An indication that the interphase between meiosis-I and meiosis-II is rapid in Bromus is that the stage is difficult to find.

The following similarities are found in mitosis and the meiotic divisions: Globules are present in prophase which generally disappear by metaphase (see below). In meiosis-I and meiosis-II globules appear in the area of the chromosome groups at the poles at late anaphase

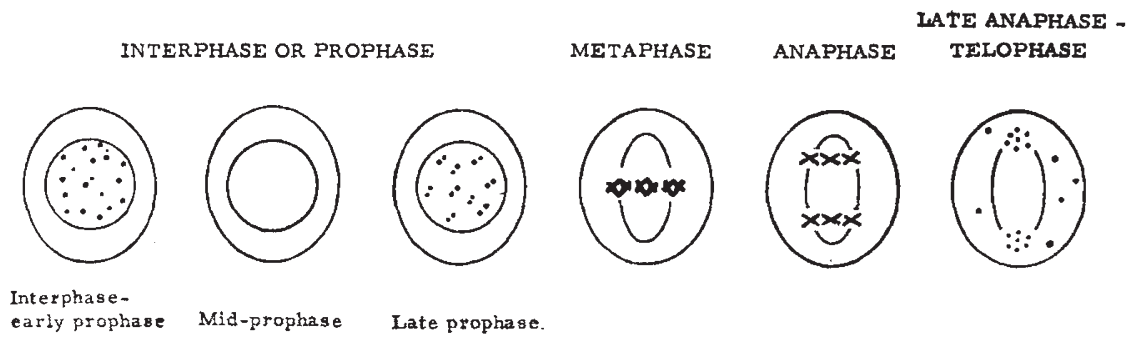

MEIOSIS I
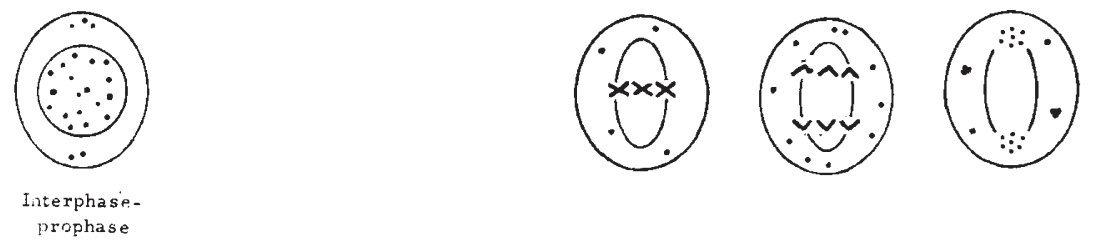

MEIOSIS II
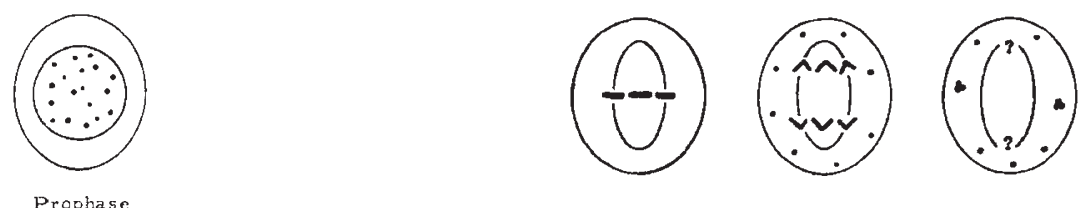

PRE-MEIOTIC MITOSIS

FrG. 3.-Diagram showing globules and aggregates, excluding the nuclear body, at various stages of meiosis and mitosis.

and globules are present in nuclei at telophase; the presence of globules at the poles is somewhat uncertain in pre-meiotic mitosis. The following differences are found: The numerous paired globules that appear at late prophase of meiosis-I (diakinesis) do not arise in late prophase of mitosis or meiosis-II. The scattered globules present at late metaphase and anaphase of mitosis and meiosis-II and the aggregates they sometimes form are not found in comparable stages of meiosis-I.

The nuclear body forms by aggregation of globule-primordia during early prophase of meiosis-I (Walters, I 966). The tiny globules present in early pre-meiotic interphase may be incorporated in the primordia, or they may disappear during late interphase and leptotene when the nuclear body primordia arise. The second suggestion is consistent 


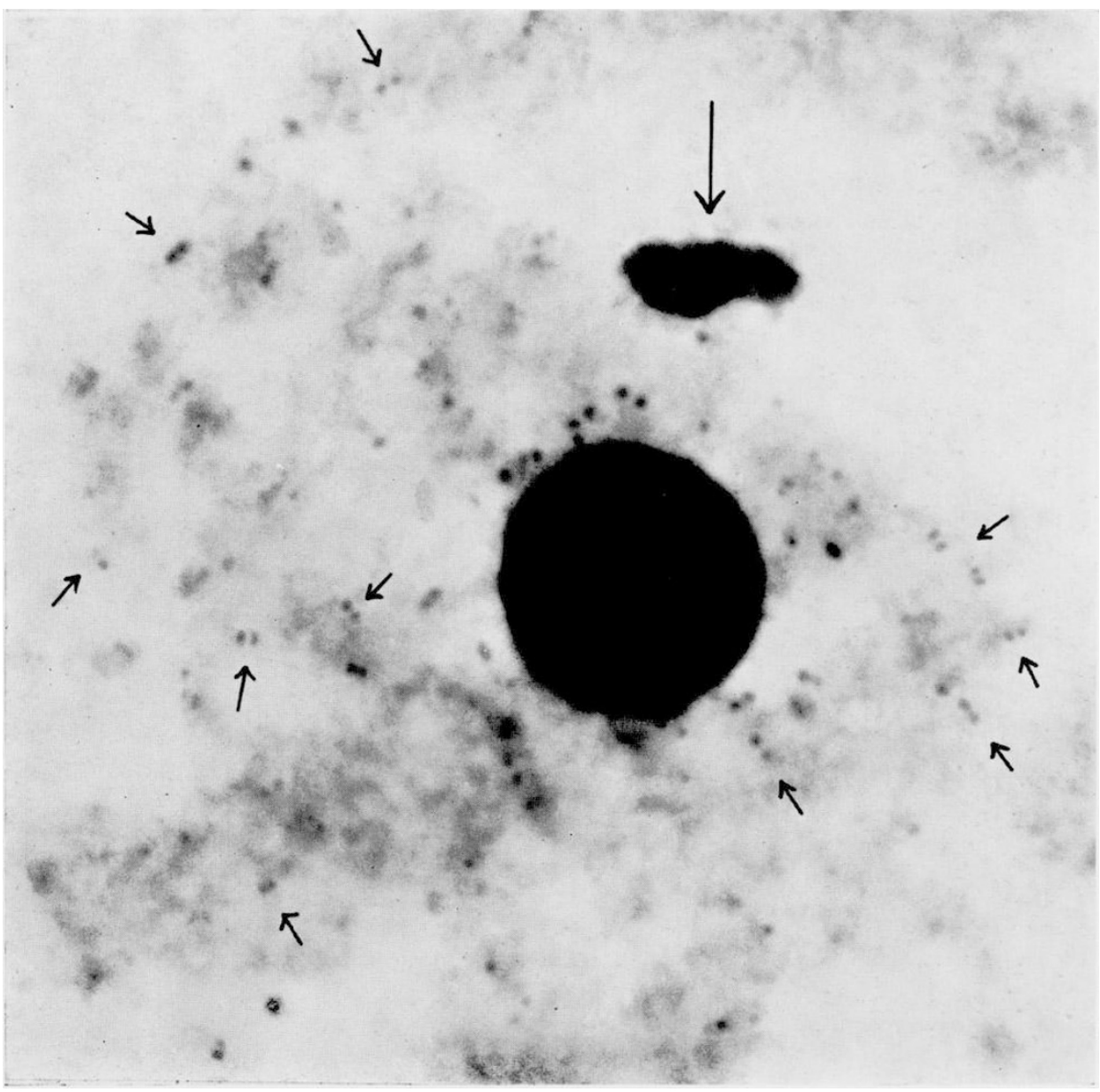

Plate I

Non-chromosomal entities in mitosis and meiosis of Bromus arizonicus. 
with the observation that globules present in interphase gradually disappear during prophase of pre-meiotic mitosis and meiosis-II; the disappearance of globules so much earlier in prophase of meiosis-I could be attributed to the length of this stage.

It has been demonstrated in many materials that RNA synthesis occurs continuously in mitosis and meiosis except during the period of chromosome contraction from late prophase through anaphase. In mitosis of Allium and Nigella, chromosomal RNA synthesis is maximal at interphase, somewhat less at early prophase, and absent at metaphase; it resumes at late telophase (Das, I 963). In orthopteran species chromosomal RNA synthesis occurs throughout meiotic prophase, decreases during diakinesis, ceases at metaphase and resumes at telophase; chromosomes are synthetically active at prophase-II and inactive at metaphase-II and anaphase-II (Henderson, I964). In the grasshopper Melanoplus, RNA is synthesised during the entire mitotic cycle except during the time of maximum contraction of the chromosomes; continuous RNA synthesis occurs in pre-meiotic interphase and early meiotic prophase, ceases during diakinesis, and resumes when the chromosomes return to a diffuse condition after meiosis-II (Muckenthaler, 1964). In Bromus arizonicus the globules appear primarily during interphase and early prophase and again at anaphase and telophase-during the stages in which maximal chromosomal RNA synthesis has been demonstrated in other materials. Possibly these globules are derived from the chromosomes and their formation is related to RNA synthesis during specific stages of division. In this event the appearance of globules in late prophase of meiosis-I which are not formed in mitosis or meiosis-II, and the presence of globules in late metaphase and early anaphase of mitosis and meiosis-II which are absent in meiosis-I would indicate differences in synthetic activities of chromosomes at corresponding stages of these divisions. It has been shown that diakinesis chromosomes are active in RNA synthesis (Henderson, 1964; Muckenthaler, 1964; Das, Siegel and Alfert, 1965), whereas mitotic chromosomes at late prophase are inactive (Prescott and Bender, 1962; Das, 1963). In certain mammalian cells RNA synthesis occurs during the entire mitotic cycle, although it is greatly decreased during metaphase and anaphase (Konrad, I963).

In a recent publication "spherical nuclear bodies" were described in meristematic cells of Allium, Vicia and Raphanus (Lafontaine, r965). These structures, which were present in interphase, pre-prophase and prophase nuclei, showed cytochemical and ultrastructural similarities with the nucleolus. The suggestion was made that these ribonucleoprotein bodies may have originated from the nucleolus or from specific chromosomal loci. Such spherical bodies may correspond with those observed in Bromus during interphase and prophase of pre-meiotic mitosis and meiosis-II. No globules such as those observed in Bromus were detected at metaphase, anaphase or telophase in Vicia.

The nuclear body in Bromus contains RNA, proteins and lipids and 
probably arises by synthetic activity of chromosomes during very early prophase of meiosis. The globules also may result from synthetic activities of chromosomes at certain stages of division, and may have a similar constitution. But these structures differ in various respects. The nuclear body appears only in meiosis. One body is formed in each microsporoctye of $B$. arizonicus, and it persists from zygotene through telophase-II. Globules are formed in various stages of mitosis and meiosis. The globules and small aggregates they sometimes form may vary in frequency among microsporocytes and individuals of $B$. arizonicus, and are of relatively brief duration. It is therefore suggested that the " nuclear body" and the "globules" are two separate kinds of structures that result from synthetic activities of chromosomes at different stages of division.

\section{SUMMARY}

I. Non-chromosomal "globules" are visible in nuclei and cytoplasm of mitotic and meiotic cells of Bromus arizonicus after a treatment that stains nucleoli and related bodies.

2. In pre-meiotic mitosis and meiosis-II the globules are absent only during metaphase. In meiosis-I they are absent only during metaphase and early anaphase. Certain paired globules arise only in late prophase of meiosis-I, scattered globules found at late metaphase and anaphase of mitosis and meiosis-II and the small aggregates they sometimes form are not found in comparable stages of meiosis-I.

3. There is some variation among microsporocytes and individuals in frequency of globules, particularly in late metaphase-II and anaphase-II.

4. There is no indication that globules contain DNA. Lipoproteins may be present but RNA in the cytoplasm prevents identification of globules after staining with Azure B.

5. The globules appear primarily during the stages in which maximal chromosomal RNA synthesis has been demonstrated in other materials. The globules may represent materials liberated from the chromosomes and their formation may be related to RNA synthesis.

6. It is suggested that synthetic activities of chromosomes at different stages of division result in two separate structures-the " nuclear body" and the "globules".

Acknowledgments.-I am grateful to Dr Spencer W. Brown, Dr Nirmal K. Das, and Dr James L. Walters for critical reading of the manuscript.

\section{REFERENCES}

DAS, N. K. 1963. Chromosomal and nucleolar RNA synthesis in root tips during mitosis. Science, I4O, 1231-1233.

DAS, N. K., SIEGEL, ELSIE P., AND ALFERT, M. 1965. Synthetic activities during spermatogenesis in the locust. Four. Cell Biol., 25, 387-395.

FABERGE, A. C. 1945. Snail stomach cytase, a new reagent for plant cytology. Stain Tech., 20, I-4. 
FLAX, M. H., AND HIMES, M. H. I952. A microspectrophotometric analysis of metachromatic staining of nucleic acids in tissues. Physiol. Zool., 25, 297-3 II.

HENDERSON, S. A. I964. RNA synthesis during male meiosis and spermatogenesis. Chromosoma, 15, 345-366.

KONRAD, CAROL G. I963. Protein synthesis and RNA synthesis during mitosis in animal cells. Four. Cell Biol., 19, 267-277.

LAFONTAINE, J. G. I965. A light and electron microscope study of small, spherical nuclear bodies in meristematic cells of Allium cepa, Vicia faba, and Raphanus sativus. Jour. Cell Biol., 26, I-I 7.

LAFONTAine, J. G., AND chouinard, L. A. 1963. A correlated light and electron microscope study of the nucleolar material during mitosis in Vicia faba. Jour. Cell. Biol., 17, I67-201.

MUCKENTHALER, F. A. 1964. Autoradiographic study of nucleic acid synthesis during spermatogenesis in the grasshopper, Melanoplus differentialis. Exper. Cell Res., 35, 53 I -547 .

PRESCOTT, D. M., AND BENDER, M. A. 1962. Synthesis of RNA and protein during mitosis in mammalian tissue culture cells. Exper. Cell Res., 26, 260-268.

RATTENBURY, J. A. 1952. Specific staining of nucleolar substance with acetocarmine. Stain Tech., 27, I I3-1 20.

walters, marta s. 1963. A nuclear body in meiosis of Bromus. Chromosoma, 14, $423-450$.

WALTERS, MARTA S. 1966. Development and chemical constitution of a nuclear body in microsporocytes of Bromus. Heredity, 21, I 73-181. 